\title{
NÍVEL DE CONHECIMENTO DOS DIRIGENTES DE 299 PEQUENAS EMPRESAS DO SUL DE SANTA CATARINA SOBRE CONCEITOS DA GESTÃO FINANCEIRA
}

Silvete Moterle ${ }^{1}$

Rodney Wernke ${ }^{2}$

Ivone Junges ${ }^{2}$

${ }^{1}$ Universidade Comunitária da Região de Chapecó

${ }^{2}$ Universidade do Sul de Santa Catarina (UNISUL) 


\section{NÍVEL DE CONHECIMENTO DOS DIRIGENTES DE 299 PEQUENAS EMPRESAS DO SUL DE SANTA CATARINA SOBRE CONCEITOS DA GESTÃO FINANCEIRA}

Resumo: Objetivou identificar o nível de conhecimento sobre conceitos financeiros dos gestores de pequenas empresas do sul catarinense. A pesquisa se caracteriza como descritiva, com abordagem quantitativa e utilização do procedimento survey para coligir dados de 299 firmas. Após breve revisão da literatura, foram apresentados os dados levantados acerca do nível de conhecimento sobre os conceitos abrangidos. Os resultados destacam que ao menos $55 \%$ dos gestores possuem conhecimento sobre os conceitos pesquisados, mas esse contingente não ultrapassou os $75 \%$ em qualquer dos itens investigados. Dessumiu-se que o menor nível de conhecimento dos gestores refere-se ao conceito de liquidez corrente. Por outro lado, os conceitos mais conhecidos pelos gestores estão vinculados à contabilidade financeira (Ativo Circulante, Passivo Circulante e Demonstração do Resultado). Outra constatação é que os gestores das indústrias possuem nível de conhecimento mais elevado sobre os itens pesquisados quando comparados aos das firmas comerciais e de serviços.

Palavras-chave: Finanças. Conhecimento dos gestores. Pequenas empresas.

\section{Introdução}

As micro e pequenas empresas (MPEs) representam uma considerável fatia da economia brasileira. Contudo, o alinhamento e o sucesso destes negócios são um grande desafio aos empreendedores visto que, na grande maioria, estes não possuem conhecimentos técnicos sobre gestão financeira, pois priorizam a atividade principal do empreendimento.

Nesse sentido, Santos, Dorow e Beuren (2016) mencionam que as MPEs tornaram-se ícones na economia do Brasil, sendo responsáveis por parte expressiva dos empregos formais, bem como auxiliam na distribuição de renda, arrecadação de tributos e desenvolvimento de certas regiões. Ainda, aduzem que a falta de aprimoramento dos gestores e a dificuldade com o conhecimento de instrumentos gerenciais têm contribuído para inibir o crescimento destas empresas, pois muitas decisões são tomadas de forma intuitiva, não levando em consideração os demonstrativos contábeis e as informações gerenciais oriundas para amparar as decisões e dar robustez ao planejamento.

Esse posicionamento é corroborado por Albuquerque (2004) quando ressalta a existência de um grave problema no processo de gerenciamento das micro e pequenas empresas, sendo que considerável parte das decisões são tomadas intuitivamente pelos seus gestores e sem considerar informações financeiras e mercadológicas. Na mesma direção, Stroeher e Freitas (2006) defendem que a falta de conhecimentos contábeis dos empresários das pequenas empresas faz com que estes não consigam avaliar a importância de tais informações; ou seja, a relevância dos demonstrativos e controles contábeis e o aporte de informações gerenciais não são analisados no processo de gestão destas entidades.
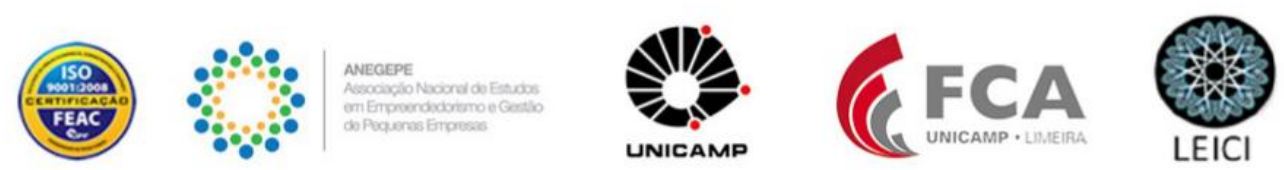
Por sua vez, Marion (2015) também considera a falta do uso de artefatos de contabilidade na gestão das empresas como um forte motivo do insucesso destas, sendo que o referido autor pugna que entre as três principais razões de falências ou insucessos da empresa, uma delas é a falta de planejamento financeiro ou a ausência total do fluxo de caixa. Opinião assemelhada é apresentada por Marques et al. (2016) quando alegam que as empresas necessitam repensar suas práticas gerenciais para não submergirem às demandas do acirramento da concorrência, qualificando o seu sistema de controle gerencial com o uso de ferramentas e conceitos financeiros.

Entretanto, algumas pesquisas (SANTOS; FERREIRA; FARIA, 2009; MONTEIRO; BARBOSA, 2011; ALBUQUERQUE et al. 2013; SANTOS; DOROW; BEUREN, 2016; KLEIN; ALMEIDA, 2017) relataram que as pequenas empresas têm dificuldades para utilizar instrumentos contábeis (como demonstrativo de resultado, balanço patrimonial, indicadores de desempenho acerca de solvência etc.), financeiros (como projeção do fluxo de caixa operacional, cálculo da necessidade de investimento em capital de giro etc.) e de custos (como ponto de equilíbrio, margem de contribuição, taxa de marcação etc.).

Essa realidade de pouco conhecimento sobre esses temas financeiros provavelmente pode estar presente no contexto das micro e pequenas empresas sediadas na microrregião da Amurel (Associação dos Municípios da Região de Laguna), sul de Santa Catarina. Em virtude disso, este estudo pretende responder a seguinte questão de pesquisa: qual o nível de conhecimento dos gestores de micro e pequenas empresas da microrregião da Amurel sobre determinados conceitos financeiros? Para tanto, foi estabelecido como objetivo de estudo identificar o nível de conhecimento sobre conceitos financeiros dos gestores de micros e pequenas empresas da microrregião mencionada.

O foco do presente estudo se justifica pela importância econômica das MPEs no cenário nacional. Nesse sentido, o Serviço Brasileiro de Apoio às Micro e Pequenas Empresas SEBRAE (2014) evidenciou que as MPEs, somadas aos MEI (Micro Empreendedores Individuais) representam $98,1 \%$ do total de empresas existentes no Brasil, onde empregam mais de 13 milhões de trabalhadores formais e são responsáveis por $27 \%$ do PIB brasileiro.

Além disso, conforme Oliveira et al. (2015), os estudos que envolvem os gestores de micro e pequenas empresas no Brasil ainda são escassos e insuficientes frente à relevância destas organizações no mercado nacional, o que é uma lacuna de pesquisa a ser melhor explorada. Destaca-se também que não há, até o presente momento, estudo com o mesmo enfoque na delimitação territorial ora priorizada (sul de Santa Catarina).

\section{Referencial teórico}

No âmbito da gestão financeira esta pesquisa priorizou os conceitos de projeção de fluxo de caixa operacional, ciclo operacional, ciclo de caixa e necessidade de investimento em capital de giro.

Quanto ao conceito de projeção de fluxo de caixa, de acordo com Santos e Veiga (2014) consiste em um demonstrativo de todas as entradas e saídas previstas para um determinado período. Este instrumento possibilita avaliar a situação financeira da empresa e identificar se haverá saldo positivo ou negativo de recursos. Ainda, para manterem a continuidade e a normalidade de suas operações, as empresas precisam liquidar corretamente seus compromissos e possuir conhecimento do respectivo saldo de caixa, visto que este demonstrativo proporciona

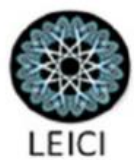


informações que auxiliam os usuários na avaliação dos ativos líquidos de uma entidade, sua estrutura financeira (inclusive sua liquidez e solvência) e sua capacidade de alterar os valores e prazos dos fluxos de caixa a fim de adaptá-los às mudanças necessárias (WERNKE et al. 2016).

No que se refere ao conceito de ciclo operacional, Braga, Nossa e Marques (2004) asseveram que este abrange todo o período de movimentação da mercadoria ou da matériaprima dentro da empresa até que o valor da venda seja recebido. Assim, envolve a compra da mercadoria, o período de estocagem e o ciclo de caixa, o que pode influenciar significativamente o resultado financeiro obtido pela empresa. Por seu turno, Santos, Ferreira e Faria (2009) referem-se ao ciclo operacional como um dos fatores determinantes para garantir a liquidez da empresa e sua necessidade de capital de giro.

Quanto ao ciclo de caixa (também denominado ciclo financeiro ou ciclo de conversão de caixa), este representa o período de tempo desde o desembolso para pagamento dos fornecedores até o recebimento do cliente (SOUZA, 1997; LEMES JÚNIOR; RIGO; CHEROBIM, 2005). No mesmo sentido, Sousa (2016) define ciclo de conversão de caixa como o período que a empresa leva para transformar sua produção em caixa, devendo ser calculado somando-se os dias de estoque da mercadoria e recebimento das vendas e subtraindo-se o total de dias para pagamento dos fornecedores. Quanto ao benefício de mensurar esse indicador, Maqbool e Farooq (2016) evidenciaram que o fluxo de conversão de caixa está diretamente associado à rentabilidade empresarial, pois quanto menor for o fluxo de conversão de caixa, maior será a rentabilidade do negócio.

No que tange ao conceito de necessidade de investimento em capital de giro, Ferreira et al. (2011) o definem como uma parcela de capital da empresa aplicada em seu ciclo operacional. Sobre a importância da adequada gestão do capital de giro, um levantamento realizado pelo SEBRAE (2007) concluiu que a principal causa de mortalidade das MPEs no Brasil é a má gestão deste tipo de capital. Todavia, a pesquisa de Domingues et al. (2017) envolvendo 2.000 MPEs e 800 MEIs (Micro Empreendedor Individual) do estado de São Paulo concluiu que ao dar início as atividades, cerca de $39 \%$ dos empreendedores não sabiam qual era a necessidade de capital de giro para abrir o negócio. Sobre o tema é interessante ressaltar que o capital de giro é essencial para a saúde financeira de qualquer empresa, sobretudo no caso das MPEs, pois quando for mal administrado pode levar a sérios problemas financeiros (DOMINGUES et al., 2017).

Acerca dos conceitos relacionados com à contabilidade, inicialmente cabe mencionar que existem diversos fatores determinantes para o sucesso de pequenas empresas, sendo que um desses fatores é a manutenção adequada de registros e controles contábeis (RESNIK, 1990). Contudo, as informações provenientes da contabilidade somente serão úteis se os gestores dessas empresas as utilizarem de maneira oportuna, a fim de dar suporte à tomada de decisões (KOS et al., 2014). Destarte, esta pesquisa priorizou os conceitos contábeis de ativo circulante (AC), passivo circulante (PC), patrimônio líquido (PL), demonstração do resultado do exercício (DRE) e liquidez corrente (LC), investigando se estes são de conhecimento dos gestores de MPEs.

Quanto ao ativo circulante (AC), para Moura e Rêgo (2014) se refere aos ativos de maior disponibilidade, classificados em ordem de liquidez, ou seja, que podem ser consumidos ou transformados em recursos financeiros no decorrer de um exercício financeiro. No que se refere ao conceito de passivo circulante (PC), o Comitê de Pronunciamentos Contábeis - CPC 00 R1

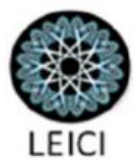


assevera que abrange as obrigações já registradas pela empresa e que deverão ser liquidadas dentro de um exercício financeiro.

No que concerne ao conceito de liquidez corrente (LC), Martins e Santos (2016) evidenciam que este indicador analisa a capacidade de pagamento de curto prazo e é calculado pela razão entre o ativo circulante e o passivo circulante. Assaf Neto e Lima (2009) esclarecem que este índice serve para retratar a saúde financeira, pois se seu valor for baixo, a empresa poderá enfrentar problemas para cumprir suas obrigações de curto prazo.

Referindo-se ao conceito de patrimônio líquido (PL), o CPC 00 R1 o define como o interesse residual nos ativos da entidade depois de deduzidos todos os seus passivos, ou seja, o valor do patrimônio líquido é encontrado por meio da subtração dos passivos circulantes e não circulantes do total do ativo da empresa.

A respeito do conceito de demonstração do resultado do exercício (DRE), D’Amato et al. (2012) esclarecem que a demonstração do resultado do exercício (DRE) é a ferramenta que comprova o resultado financeiro das empresas em determinado período, revelando se houve lucro ou prejuízo nas suas operações. Almeida e Martins (2014, p. 63) evidenciam que esta demonstração "apresenta o desempenho da entidade na perspectiva do regime de competência, contribuindo para o monitoramento das operações e fornecendo informações para a tomada de decisões".

\subsection{Estudos anteriores assemelhados}

Inicialmente cabe salientar que não foram encontrados estudos com o mesmo objetivo proposto neste trabalho em pesquisas efetuadas nas bases de dados Google Acadêmico, Portal de Periódicos da Capes e base de dados Spell. Para tanto, nas referidas pesquisas foram adotados os termos de busca equivalentes a "conhecimento de conceitos financeiros" e "conhecimento+ gestores financeiros", onde não foram identificados artigos que atendessem aos critérios de busca.

Entretanto, foi possível acessar diversos estudos que analisaram instrumentos de controles financeiros e contábeis, bem como a importância atribuída aos mesmos por gestores de micro e pequenas empresas. Então, por assemelharem-se ao proposto nesta pesquisa, os referidos estudos são comentados na sequência.

\section{Quadro 1 - Pesquisas assemelhadas}

\begin{tabular}{|c|c|}
\hline Autores & Principais aspectos \\
\hline $\begin{array}{l}\text { Raupp, } \\
\text { Martins e } \\
\text { Beuren }(2006)\end{array}$ & $\begin{array}{l}\text { Estudaram os instrumentos de controle de gestão utilizados nas } 250 \text { maiores empresas } \\
\text { industriais de Santa Catarina e concluíram ser grande a utilização de controles gerenciais } \\
\text { financeiros como a contabilidade de custos, o fluxo de caixa e os orçamentos. }\end{array}$ \\
\hline $\begin{array}{l}\text { Lima e } \\
\text { Imoniana } \\
(2008) \\
\end{array}$ & $\begin{array}{l}\text { Averiguaram quais os instrumentos de controles gerenciais eram utilizados por } 55 \text { MPEs de } \\
\text { São Caetano do Sul (SP) e se estes influenciavam a tomada de decisões dos gestores. } \\
\text { Concluíram que uma parcela significativa das empresas pesquisadas utilizava controles de } \\
\text { gestão para a tomada de decisões, mas poucas empregavam ferramentas de monitoramento. }\end{array}$ \\
\hline $\begin{array}{l}\text { Santos, } \\
\text { Ferreira e } \\
\text { Faria } \\
(2009)\end{array}$ & $\begin{array}{l}\text { Com o objetivo de investigar os fatores limitantes da gestão de capital de giro nas micro e } \\
\text { pequenas empresas da cidade de Viçosa (MG) indagaram } 172 \text { proprietários de MPEs. Os } \\
\text { resultados apontaram diversas limitações na gestão financeira, visto que parcela expressiva } \\
\text { das firmas pesquisadas não adotava as práticas de gestão financeira e não eram adeptas da } \\
\text { adoção de ferramentas de controle. }\end{array}$ \\
\hline Monteiro & $\begin{array}{l}\text { Averiguaram a utilização de instrumentos da controladoria por MPEs para auxiliar na gestão } \\
\text { empresarial. Os resultados apurados enfatizam que: (i) as ferramentas de controladoria não }\end{array}$ \\
\hline
\end{tabular}

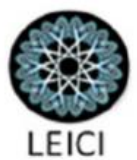




\begin{tabular}{|c|c|}
\hline $\begin{array}{c}\text { e Barbosa } \\
\text { (2011) }\end{array}$ & $\begin{array}{l}\text { eram utilizadas de forma plena; (ii) os micro e pequenos empresários possuíam visão da } \\
\text { necessidade de integração entre gestão e o fornecimento de informações para decisões mais } \\
\text { coerentes e (iii) reconhecem a necessidade de ampliação dos conhecimentos sobre estratégia, } \\
\text { controle, finanças e contabilidade gerencial. }\end{array}$ \\
\hline $\begin{array}{l}\text { Carvalho } \\
\text { e Lima } \\
(2011)\end{array}$ & $\begin{array}{l}\text { Analisaram as práticas gerenciais utilizadas por } 45 \text { empresas da cidade de Sousa (PB) e } \\
\text { buscaram identificar clusters de acordo com as opiniões dos gestores entrevistados, a fim de } \\
\text { conhecer as estratégias relativas às práticas de gerenciamento daquelas empresas. Apuraram } \\
\text { que as empresas estudadas utilizam práticas gerenciais com ordenação intuitiva e com base } \\
\text { nas experiências de cada gestor. No entanto, identificaram que isso ocorre de forma } \\
\text { desordenada e informal, sem definição de planos estruturados e consistentes. }\end{array}$ \\
\hline $\begin{array}{l}\text { Albuquerque } \\
\text { et al. } \\
\text { (2013) }\end{array}$ & $\begin{array}{l}\text { Avaliaram a utilização (em termos de padrão e intensidade) de indicadores e relatórios } \\
\text { contábeis nas MPEs do estado do Amazonas, revelando que aquelas MPEs não usavam com } \\
\text { frequência indicadores, relatórios e informações contábeis para tomada de decisão. }\end{array}$ \\
\hline $\begin{array}{l}\text { Campos e } \\
\text { Gáudio } \\
(2015)\end{array}$ & $\begin{array}{l}\text { Objetivaram identificar se as MPEs da região metropolitana do Rio de Janeiro utilizavam } \\
\text { ferramentas de controle gerencial no processo de gestão. Envolvendo vinte MPEs, concluíram } \\
\text { que as firmas com mais tempo de mercado utilizavam mais os controles gerenciais para dar } \\
\text { suporte às decisões. Ainda, entre as ferramentas utilizadas destacaram-se os controles de } \\
\text { caixa, contas a pagar, contas a receber e de custos. }\end{array}$ \\
\hline $\begin{array}{l}\text { Borges } \\
\text { e Leal } \\
(2015)\end{array}$ & $\begin{array}{l}\text { Investigaram a importância atribuída pelos gestores de MPEs às informações contábeis } \\
\text { gerenciais, bem como a periodicidade da utilização destas em } 75 \text { MPEs de Uberlândia (MG). } \\
\text { Dessumiram que os gestores avaliam as informações contábeis gerenciais como "muito } \\
\text { importante"; mas em muitas ocasiões não as utilizam por falta de conhecimento a respeito. }\end{array}$ \\
\hline $\begin{array}{c}\text { Santos, } \\
\text { Dorow e } \\
\text { Beuren } \\
(2016)\end{array}$ & $\begin{array}{l}\text { Investigaram os instrumentos e procedimentos gerenciais utilizados por micros, pequenas e } \\
\text { médias empresas, bem como a importância atribuída pelos gestores a essas informações no } \\
\text { processo de tomada de decisões. A amostra foi composta por } 41 \text { empresas sediadas na região } \\
\text { do Alto Vale do Itajaí (SC). Os resultados demonstraram que as decisões normalmente são } \\
\text { tomadas com base na experiência do proprietário, sendo que muitas vezes este desconhece a } \\
\text { utilidade das informações contábeis. Em muitos casos, a contabilidade da empresa não reflete } \\
\text { a sua real situação, visto haver determinado nível de informalidade nas operações cotidianas. }\end{array}$ \\
\hline $\begin{array}{l}\text { Almeida, } \\
\text { Pereira } \\
\text { e Lima } \\
(2016)\end{array}$ & $\begin{array}{l}\text { Realizaram estudo com o propósito de identificar os instrumentos de controle de gestão } \\
\text { utilizados por micros e pequenas empresas de Santa Catarina. A pesquisa abrangeu } 76 \text { MPEs } \\
\text { e apurou que um número significativo destas utiliza controles de gestão por meio de } \\
\text { instrumentos financeiros e não financeiros, destacando-se como controles financeiros o } \\
\text { controle de contas a pagar e a receber, controle de custos e o fluxo de caixa. }\end{array}$ \\
\hline $\begin{array}{c}\text { Wernke e } \\
\text { Junges } \\
(2016)\end{array}$ & $\begin{array}{l}\text { Buscaram identificar o grau de utilização de dois demonstrativos contábeis, Balanço } \\
\text { Patrimonial (BP) e Demonstração do Resultado do Exercício (DRE) em } 207 \text { empresas } \\
\text { sediadas em Santa Catarina. A pesquisa realizada demonstrou que a DRE não era utilizada } \\
\text { em } 28,02 \% \text { das empresas da amostra e } 31,88 \% \text { não utilizavam o Balanço Patrimonial. Ainda, } \\
\text { identificaram que } 80,68 \% \text { dos gestores pesquisados consideraram a DRE importante para } \\
\text { melhorar o desempenho da empresa e apenas } 62,80 \% \text { consideraram o BP importante para } \\
\text { aperfeiçoar a performance empresarial. }\end{array}$ \\
\hline $\begin{array}{l}\text { Panosso } \\
\text { et al. } \\
(2017)\end{array}$ & $\begin{array}{l}\text { Procuraram conhecer a influência do conhecimento, a utilização e o grau de importância } \\
\text { atribuídos às ferramentas de controle gerencial no desempenho empresarial em } 149 \\
\text { organizações industriais com atuação no Estado do Paraná. O estudo revelou que a maioria } \\
\text { dos gestores conhece as ferramentas de controle gerencial, mas há um baixo percentual de } \\
\text { utilização e que entre as ferramentas investigadas aquela mais utilizada foi o orçamento. }\end{array}$ \\
\hline $\begin{array}{l}\text { Klein e } \\
\text { Almeida } \\
(2017)\end{array}$ & $\begin{array}{l}\text { Pesquisaram } 23 \text { indústrias paranaenses com o propósito de investigar se a adoção de práticas } \\
\text { de contabilidade gerencial é influenciada por fatores contingenciais. O resultado apontou uma } \\
\text { maior utilização de práticas de contabilidade gerenciais tradicionais em detrimento das } \\
\text { técnicas mais sofisticadas ou de estágios mais evoluídos. Contudo, as práticas gerenciais mais } \\
\text { modernas foram avaliadas pelos entrevistados como muito importantes. }\end{array}$ \\
\hline
\end{tabular}

Fonte: elaborado pelos autores. 


\section{Procedimentos Metodológicos}

Esta pesquisa classifica-se como descritiva, quantitativa e survey. De acordo com Gil (2009), a pesquisa descritiva busca apresentar as características de determinada população ou fenômeno. Em relação ao problema de pesquisa, classifica-se como abordagem quantitativa, com aplicação de técnica estatística para análise e interpretação dos dados coletados, conforme preconizado por Richardson et al. (1999). Quanto ao procedimento de coleta de dados, foi utilizado o levantamento (survey), que para Freitas et al. (2000) é um método utilizado para pesquisas de maior abrangência e consiste em obter dados ou informações sobre ações, características ou opiniões de determinado grupo de pessoas.

Nessa direção, a coleta de dados ocorreu no período de junho a outubro de 2017 e envolveu 299 empresas, sendo 232 não-fabris e 67 industriais, sediadas na microrregião da Associação dos Municípios da Região de Laguna - AMUREL (sul de Santa Catarina), por meio da aplicação de questionários específicos. Os questionários foram aplicados aos gestores em suas empresas por um grupo de alunos do curso de Administração de uma universidade comunitária da região abrangida, devidamente treinados para tal finalidade.

Quanto às características do questionário, este foi dividido em três partes, sendo que a primeira visava conhecer algumas características das empresas participantes e dos respondentes. Por sua vez, a segunda parte investigou sobre a frequência de uso e a importância atribuída aos indicadores não financeiros pelos administradores destas empresas, enquanto que a terceira parte buscou identificar o conhecimento dos gestores da MPEs sobre determinados conceitos financeiros.

Convém destacar que o referido instrumento de pesquisa continha questões abertas, questões de múltiplas escolhas e algumas perguntas que envolviam escala do tipo "Likert", com escala de importância que ia de "0" a "3", onde se considerava o nível "3" como conhece profundamente e o " 0 " como desconhece a respeito do assunto. A opção por utilizar uma escala do tipo Likert de quatro pontos coaduna-se com a posição de Richardson et al. (1999) que aduzem que isso proporciona informação de melhor qualidade que uma simples dicotomia entre as opiniões de acordo ou desacordo.

Ainda, quanto às etapas de processamento e análise dos dados coligidos, estes foram tabulados em planilha Excel, onde foi empregada estatística descritiva (frequência e número de respostas) para sintetizar os resultados e facilitar a interpretação dos "achados" do estudo.

\section{Análise e Interpretação dos Resultados}

Das respostas obtidas foram extraídas as características principais das 299 empresas que participaram da pesquisa conforme elencado a seguir.

Quanto ao setor de atuação foi constatado que 46,38\% são empresas comerciais; $29,59 \%$ são prestadoras de serviços e $22,22 \%$ são indústrias. No que diz respeito ao tempo de existência, apurou-se que 45,89\% das companhias atuam há mais de 10 anos no mercado; que 23,67\% já funcionam entre 5 e 10 anos e que 13,53\% têm acima de 10 anos de atuação.

Em relação ao quadro de funcionários foi registrado que $62,32 \%$ das empresas possuem até 10 funcionários; $21,74 \%$ mantém entre 11 e 50 empregados e as restantes $(15,94 \%)$ tinham entre 51 e 100 colaboradores. Acerca da forma de tributação vigente, 60,87\% das participantes são optantes pelo "Simples", 8,21\% são registradas como MEI e as demais companhias são optantes pelo regime do Lucro Real $(20,77 \%)$ ou pelo Lucro Presumido $(9,66 \%)$.

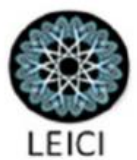




\subsection{Conhecimento dos gestores sobre conceitos de gestão financeira}

Neste tópico da pesquisa as questões indagavam sobre o conhecimento acerca dos conceitos de projeção do fluxo de caixa operacional, ciclo operacional, ciclo de caixa e necessidade de investimento em capital de giro. Nesse sentido, na Tabela 1 estão os resultados relacionados à projeção do fluxo de caixa operacional.

Tabela 1 - Projeção do Fluxo de Caixa Operacional

\begin{tabular}{lrrrrrr}
\hline \multirow{2}{*}{ Nível } & \multicolumn{2}{c}{ Total } & \multicolumn{2}{c}{ Não-fabris } & \multicolumn{2}{c}{ Indústrias } \\
& Freq. & $\%$ & Freq. & $\%$ & Freq. & $\%$ \\
\hline 0-Desconhece & 36 & 12,0 & 33 & 14,2 & 3 & 4,5 \\
1-Conhece pouco, insuficiente para usar & 76 & 25,4 & 59 & 25,4 & 17 & 25,4 \\
2-Conhece suficiente para usar & 141 & 47,2 & 104 & 44,8 & 37 & 55,2 \\
3-Conhece profundamente & 46 & 15,4 & 36 & 15,5 & 10 & 14,9 \\
Total & 299 & 100 & 232 & 100 & 67 & 100 \\
\hline
\end{tabular}

Fonte: elaborada pelos autores.

Pelos dados da Tabela 1 , em relação ao conceito de projeção do fluxo de caixa operacional constatou-se que 47,2\% (141) dos gestores afirmaram possuir conhecimento suficiente para usar esta ferramenta e 15,4\% (46) do total da amostra revelaram que conhecemno profundamente. Com isso, pode-se considerar que tal conceito está bem difundido nas micro e pequenas empresas pesquisadas, visto que 187 gestores (equivalente a $62,6 \%$ das entidades abrangidas) aduziram que têm domínio suficiente a respeito.

Nesse contexto, apurou-se também que tal conhecimento é maior no contingente de empresas industriais, em comparação com as não-fabris. Contudo, 25,4\% (76) dos respondentes informaram que possuem pouco conhecimento sobre o conceito em tela, não sendo suficiente para utilização no dia a dia das empresas e 12\% (36) demonstraram desconhecimento total sobre fluxo de caixa operacional.

Na sequência foi investigado o nível de conhecimento dos gestores acerca do conceito de ciclo operacional, cujos resultados estão expostos na Tabela 2.

Tabela 2 - Ciclo Operacional

\begin{tabular}{lrrrrrr}
\hline \multirow{2}{*}{ Nível } & \multicolumn{2}{c}{ Total } & \multicolumn{2}{c}{ Não-fabris } & \multicolumn{2}{c}{ Indústrias } \\
& Freq. & $\%$ & Freq. & $\%$ & Freq. & $\%$ \\
\hline 0-Desconhece & 63 & 21,1 & 53 & 22,8 & 10 & 14,9 \\
1-Conhece pouco, insuficiente para usar & 71 & 23,7 & 53 & 22,8 & 18 & 26,9 \\
2-Conhece suficiente para usar & 125 & 41,8 & 95 & 40,9 & 30 & 44,8 \\
3-Conhece profundamente & 40 & 13,4 & 31 & 13,4 & 9 & 13,4 \\
Total & 299 & 100 & 232 & 100 & 67 & 100 \\
\hline
\end{tabular}

Fonte: elaborada pelos autores.

Como visto, a pesquisa demonstrou que 55,2\% (165) dos respondentes possuem conhecimento suficiente para usar ou têm conhecimento aprofundado a respeito do tema. Por outro lado, 23,7\% (71) possuem pouco conhecimento e 21,1\% (63) afirmaram que desconhecem totalmente o conceito de ciclo operacional. Ao comparar os dois segmentos empresariais constatou-se que há pouca divergência nos níveis de conhecimento entre os mesmos, com pequena vantagem para as empresas fabris. 
Na sequência foi inquirido sobre o nível de compreensão do conceito de ciclo de caixa (ou ciclo financeiro). Nesse rumo, os dados relacionados estão apresentados na Tabela 3.

Tabela 3 - Ciclo de Caixa

\begin{tabular}{lrrrrrr}
\hline \multirow{2}{*}{ Nível } & \multicolumn{2}{c}{ Total } & \multicolumn{2}{c}{ Não-fabris } & \multicolumn{2}{c}{ Indústrias } \\
& Freq. & $\%$ & Freq. & $\%$ & Freq. & $\%$ \\
\hline 0-Desconhece & 47 & 15,7 & 43 & 18,5 & 4 & 6,0 \\
1-Conhece pouco, insuficiente para usar & 58 & 19,4 & 45 & 19,4 & 13 & 19,4 \\
2-Conhece suficiente para usar & 152 & 50,8 & 110 & 47,4 & 42 & 62,7 \\
3-Conhece profundamente & 42 & 14,0 & 34 & 14,7 & 8 & 11,9 \\
Total & 299 & 100 & 232 & 100 & 67 & 100 \\
\hline
\end{tabular}

Fonte: elaborada pelos autores.

A partir das respostas obtidas percebe-se que o conhecimento dos gestores em relação ciclo de caixa (ciclo financeiro) está bem disseminado porque 64,8\% informaram que conhecem a respeito o suficiente para usar ou em profundidade. Nessa direção, apurou-se que nas empresas industriais esse conhecimento é maior, pois $62,7 \%$ dos gestores possuem conhecimento suficiente para utilizá-lo e $11,9 \%$ conhecem-no profundamente. Por outro lado, $19,4 \%$ dos gestores dos dois grupos de empresas possuem pouco conhecimento a respeito e $15,7 \%$ desconhecem-no totalmente. Nesse caso, nas não-fabris esse desconhecimento total é maior: $18,5 \%$ contra $6,0 \%$ das empresas industriais.

Os conceitos citados anteriormente estão vinculados, direta ou indiretamente, com a Necessidade de Investimento em Capital de Giro (NICG), cujo conhecimento por parte dos gestores das firmas pesquisadas também foi mensurado. Desse modo, na Tabela 4 consta a compilação das respostas coligidas.

Tabela 4 - Necessidade de Investimento em Capital de Giro (NICG)

\begin{tabular}{lrrrrrr}
\hline \multirow{2}{*}{ Nível } & \multicolumn{2}{c}{ Total } & \multicolumn{2}{c}{ Não-fabris } & \multicolumn{2}{c}{ Indústrias } \\
& Freq. & $\%$ & Freq. & $\%$ & Freq. & $\%$ \\
\hline 0-Desconhece & 57 & 19,1 & 50 & 21,6 & 7 & 10,4 \\
1-Conhece pouco, insuficiente para usar & 72 & 24,1 & 58 & 25,0 & 14 & 20,9 \\
2-Conhece suficiente para usar & 131 & 43,8 & 94 & 40,5 & 37 & 55,2 \\
3-Conhece Profundamente & 39 & 13,0 & 30 & 12,9 & 9 & 13,4 \\
Total & 299 & 100 & 232 & 100 & 67 & 100 \\
\hline
\end{tabular}

Fonte: elaborada pelos autores.

Conforme evidenciado na Tabela 4, cerca de $43 \%$ das empresas pesquisadas revelaram que conhecem pouco ou insuficiente para usar o conceito de NICG $(24,1 \%)$ ou desconhecemno totalmente $(19,1 \%)$. Esses resultados se assemelham aos apurados por Domingues et al. (2017), que concluíram que, ao dar início às atividades, cerca de 39\% dos micros e pequenos empreendedores não possuíam entendimento sobre o valor da necessidade de capital de giro para dar suporte às atividades da empresa.

Adicionalmente, nesta pesquisa foi constatado que entre os gestores das micro e pequenas industriais abordadas, 10,4\% (7) não possuíam conhecimento algum sobre o conceito de necessidade de capital de giro e $20,9 \%$ (14) possuíam domínio insuficiente para utilizá-lo. Ainda, 55,2\% das empresas fabris conheciam o conceito de NICG de forma suficiente para usar e 13,4\% declararam conhecê-lo plenamente. Quanto à análise dos dados referente às empresas

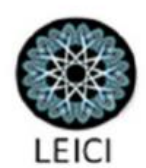


não-fabris, apurou-se que 53,4\% dos gestores $(94+30)$ afirmaram conhecer o conceito de NICG, enquanto que 25,0\% afirmaram conhecer minimamente e 21,6\% declararam que desconhecem-no.

\subsection{Conhecimento dos gestores sobre conceitos de contabilidade financeira}

No intuito de identificar o conhecimento dos gestores das micro e pequenas empresas sobre determinados conceitos da contabilidade financeira, foi perguntado sobre o nível de compreensão acerca do ativo circulante, do passivo circulante, do patrimônio líquido, da demonstração do resultado do exercício e da liquidez corrente. Destarte, na Tabela 5 consta um resumo dos dados coletados em relação ao conceito de Ativo Circulante (AC).

Tabela 5 - Ativo Circulante (AC)

\begin{tabular}{lrrrrrr}
\hline \multirow{2}{*}{ Nível } & \multicolumn{2}{c}{ Total } & \multicolumn{2}{c}{ Não-fabris } & \multicolumn{2}{c}{ Indústrias } \\
& Freq. & $\%$ & Freq. & $\%$ & Freq. & $\%$ \\
\hline 0-Desconhece & 55 & 18,4 & 48 & 20,7 & 7 & 10,4 \\
1-Conhece pouco, insuficiente para usar & 64 & 21,4 & 49 & 21,1 & 15 & 22,4 \\
2-Conhece suficiente para usar & 132 & 44,1 & 96 & 41,4 & 36 & 53,7 \\
4-Conhece Profundamente & 48 & 16,1 & 39 & 16,8 & 9 & 13,4 \\
Total & 299 & 100 & 232 & 100 & 67 & 100 \\
\hline
\end{tabular}

Fonte: elaborada pelos autores.

Portanto, com base na Tabela 5 se dessume que 60,2\% dos respondentes possuem conhecimento a respeito $(44,1 \%$ conhecem o suficiente e $16,1 \%$ conhecem com profundidade). No entanto, $18,4 \%$ desconhecem o conceito de Ativo Circulante e 21,4\% conhecem-no minimamente.

Ao subdividir os gestores por ramo de atuação percebeu-se que nas indústrias há um maior nível de conhecimento em relação às empresas comerciais e de prestação de serviços. Dos gestores do setor fabril indagados, $13,4 \%$ possuem conhecimento aprofundado sobre Ativo Circulante e $53,7 \%$ aduziram que conhecem o suficiente. Porém, 22,4\% pouco conhecem e 10,4\% demonstraram não possuir qualquer conhecimento sobre o assunto. Pelo prisma das empresas não fabris, $16,8 \%$ dos gestores afirmaram que conhecem fortemente o conceito de ativo circulante e $41,4 \%$ conhecem o suficiente para utilizar. Adicionalmente, $21,1 \%$ conhecem um pouco a respeito (mas de forma insuficiente para utilização) e $20,7 \%$ desconhecem totalmente o conceito pesquisado.

$\mathrm{Na}$ Tabela 6 estão evidenciados os dados referentes ao nível de conhecimento dos gestores sobre o conceito de Passivo Circulante (PC).

Tabela 6 - Passivo Circulante

\begin{tabular}{lrrrrrr}
\hline \multirow{2}{*}{ Nível } & \multicolumn{2}{c}{ Total } & \multicolumn{2}{c}{ Não-fabris } & \multicolumn{2}{c}{ Indústrias } \\
& Freq. & $\%$ & Freq. & $\%$ & Freq. & $\%$ \\
\hline 0-Desconhece & 55 & 18,4 & 48 & 20,7 & 7 & 10,4 \\
1-Conhece pouco, insuficiente para usar & 62 & 20,7 & 48 & 20,7 & 14 & 20,9 \\
2-Conhece suficiente para usar & 132 & 44,1 & 98 & 42,2 & 34 & 50,7 \\
3-Conhece Profundamente & 50 & 16,7 & 38 & 16,4 & 12 & 17,9 \\
Total & 299 & 100 & 232 & 100 & 67 & 100 \\
\hline
\end{tabular}


Fonte: elaborada pelos autores.

Pelos dados constantes na Tabela 6 infere-se que quase o mesmo contingente dos gestores que declararam possuir conhecimento sobre o conceito de ativo circulante também conhecem sobre passivo circulante. Isso provavelmente ocorre devido à similaridade das informações, bem como por serem evidenciados no mesmo demonstrativo contábil. Das frequências apresentadas concluiu-se que 17,9\% dos gestores das indústrias conhecem profundamente o conceito questionado e $50,7 \%$ conhecem-no parcialmente, mas o suficiente para que possam utilizá-lo. Entretanto, 20,9\% pouco conhecem e 10,4\% não conhecem o conceito de Passivo Circulante.

Quanto aos gestores de MPEs não fabris, 16,4\% possuem conhecimento aprofundado, $42,2 \%$ conhecem-no o suficiente para usar, 20,7\% compreendem-no infimamente e 20,7\% desconhecem o significado de Passivo Circulante.

No prosseguimento do estudo foi perguntado sobre o grau de conhecimento dos gestores sobre o conceito de patrimônio líquido (PL), conforme expresso na Tabela 7.

Tabela 7 - Patrimônio Líquido (PL)

\begin{tabular}{lrrrrrr}
\hline \multirow{2}{*}{ Nível } & \multicolumn{2}{c}{ Total } & \multicolumn{2}{c}{ Não-fabris } & \multicolumn{2}{c}{ Indústrias } \\
& Freq. & $\%$ & Freq. & $\%$ & Freq. & $\%$ \\
\hline 0-Desconhece & 37 & 12,4 & 35 & 15,1 & 2 & 3,0 \\
1-Conhece pouco, insuficiente para usar & 53 & 17,7 & 38 & 16,4 & 15 & 22,4 \\
2-Conhece suficiente para usar & 142 & 47,5 & 105 & 45,3 & 37 & 55,2 \\
3-Conhece Profundamente & 67 & 22,4 & 54 & 23,3 & 13 & 19,4 \\
Total & 299 & 100 & 232 & 100 & 67 & 100 \\
\hline
\end{tabular}

Fonte: elaborada pelos autores.

Assim, com base nos dados apresentados na Tabela 7 percebeu-se que 69,9\% dos respondentes afirmaram conhecer de forma que lhes possibilite a utilização do conceito de patrimônio líquido (47,5\% conhecem parcialmente $22,4 \%$ de modo aprofundado) e 30,1\% admitiram pouco conhecer $(17,7 \%)$ ou desconhecer totalmente $(12,4 \%)$.

Por outro ângulo, extraiu-se também as informações de que 19,4\% dos gestores industriais conhecem plenamente o conceito de PL, que 55,2\% conhecem-no parcialmente, que $22,4 \%$ conhecem-no infimamente e apenas 3,0\% desconhecem totalmente o conceito mencionado. Quanto aos gestores das empresas do ramo comercial e de serviços, 23,3\% possuem conhecimento aprofundado sobre o conceito de PL, 45,3\% conhecem o suficiente para utilizar, 16,4\% não conhecem o suficiente e $15,1 \%$ desconhecem-no.

$\mathrm{Na}$ Tabela 8 estão reportados os dados compilados quanto ao nível de conhecimento dos gestores sobre o conceito de Demonstração do Resultado do Exercício (DRE).

Tabela 8 - Demonstração do Resultado do Exercício (DRE)

\begin{tabular}{lrrrrrr}
\hline \multirow{2}{*}{ Nível } & \multicolumn{2}{c}{ Total } & \multicolumn{2}{c}{ Não-fabris } & \multicolumn{2}{c}{ Indústrias } \\
& Freq. & $\%$ & Freq. & $\%$ & Freq. & $\%$ \\
\hline 0-Desconhece & 41 & 13,7 & 37 & 15,9 & 4 & 6,0 \\
1-Conhece pouco, insuficiente para usar & 57 & 19,1 & 45 & 19,4 & 12 & 17,9 \\
2-Conhece suficiente para usar & 137 & 45,8 & 99 & 42,7 & 38 & 56,7 \\
3-Conhece Profundamente & 64 & 21,4 & 51 & 22,0 & 13 & 19,4 \\
\hline
\end{tabular}


Fonte: elaborada pelos autores.

Os dados expressos na Tabela 8 demonstram que 67,2\% dos gestores das MPEs conhecem o conceito de DRE e 32,8\% conhecem pouco ou nada a respeito.

Segregando-se por ramo de atuação restou evidente que há um maior conhecimento por parte dos gestores das MPEs industriais, sendo que neste segmento 19,4\% dos pesquisados demonstraram conhecer profundamente o conceito de DRE e 56,7\% responderam que conhecem o suficiente para usar. Ainda, 17,9\% informaram que conhecem pouco (insuficiente para utilização) e $6 \%$ declararam que desconhecem totalmente o que este demonstrativo representa. Em relação às empresas comerciais e de serviços, $22,0 \%$ dos gestores afirmaram conhecer de forma aprofundada o conceito de DRE, 42,7\% declararam conhecer suficientemente para utilização, 19,4\% conhecem-no minimamente e 15,9\% não possuem conhecimento algum sobre o assunto.

Por sua vez, na Tabela 9 estão listados os resultados da pesquisa no que concerne à Liquidez Corrente.

Tabela 9 - Liquidez Corrente (LC)

\begin{tabular}{lrrrrrr}
\hline \multirow{2}{*}{ Nível } & \multicolumn{2}{c}{ Total } & \multicolumn{2}{c}{ Não-fabris } & \multicolumn{2}{c}{ Indústrias } \\
& Freq. & $\%$ & Freq. & $\%$ & Freq. & $\%$ \\
\hline 0-Desconhece & 72 & 24,1 & 59 & 25,4 & 13 & 19,4 \\
1-Conhece pouco, insuficiente para usar & 75 & 25,1 & 62 & 26,7 & 13 & 19,4 \\
2-Conhece suficiente para usar & 125 & 41,8 & 89 & 38,4 & 36 & 53,7 \\
3-Conhece Profundamente & 27 & 9,0 & 22 & 9,5 & 5 & 7,5 \\
Total & 299 & 100 & 232 & 100 & 67 & 100 \\
\hline
\end{tabular}

Fonte: elaborada pelos autores.

Das 299 empresas abrangidas, em 9,0\% destas os gestores afirmaram conhecer fortemente o conceito de Liquidez Corrente (LC) e 41,8\% asseguraram que conhecem de forma parcial, mas suficiente para utilizá-lo. Em contrapartida, 25,1\% responderam que conhecem pouco e $24,1 \%$ declararam desconhecer tal conceito.

Nas indústrias chegou a 7,5\% o número de gestores que conhecem profundamente o conceito de LC e equivaleu a 53,7\% o contingente que afirmou conhecer de forma suficiente para utilização. Já nas MPEs não fabris, quase $10 \%$ dos gestores afirmaram que conhecem o conceito de forma plena, 38,4\% declararam que conhecem-no parcialmente, $26,7 \%$ demonstraram que pouco conhecem e $25,4 \%$ confessaram desconhecimento total sobre este indicador.

\subsection{Discussão dos resultados e cotejamento com estudos anteriores}

Os resultados deslindados nas seções precedentes permitem destacar alguns aspectos que podem ser considerados os mais relevantes.

Destarte, em relação aos conceitos inerentes à gestão financeira cabe salientar que o nível de desconhecimento sobre a projeção do fluxo de caixa operacional nas empresas comerciais e de serviços é de 39,7\% dos gestores, enquanto que nas indústrias esse contingente equivale a $29,9 \%$ dos gestores. Como essa é uma ferramenta essencial para aprimorar o controle financeiro das organizações, o número expressivo de gerentes que não dominam 
suficientemente tal instrumento pode ser considerado uma característica preocupante da gestão financeira dessas firmas de pequeno porte. Contudo, o resultado encontrado coaduna-se com o exposto por Marion (2015), o qual ressalta que muitas empresas não utilizam o fluxo de caixa no controle financeiro das atividades, sendo esta uma das prováveis causas da mortalidade precoce dos empreendimentos.

Quanto ao conceito de ciclo operacional, constatou-se que este é pouco conhecido pelos gestores, sendo que $44,8 \%$ do total de respondentes afirmaram que não conhecem-no. Nesse contexto, há uma maior predominância no comércio (onde 45,7\% não dominam esse tema) perante as empresas fabris (nas quais $41,8 \%$ dos gestores não conhecem a respeito).

Ao indagar sobre o ciclo de caixa se apurou que este conceito é compreendido por $64,9 \%$ dos gestores das 299 micros e pequenas empresas pesquisadas. Esse patamar mais elevando em relação aos conceitos citados nos parágrafos precedentes deve-se ao fato de que nas indústrias esse conhecimento está presente em 74,6\% deste tipo de firma (contra 61,2\% das demais empresas). Esse assemelhado nível de conhecimento dos conceitos de ciclo de caixa e de projeção de fluxo de caixa deve-se, provavelmente, à similaridade de parte das informações abrangidas por estes dois instrumentos gerenciais, visto que o ciclo de caixa evidencia o período entre o pagamento de fornecedores até o recebimento de clientes, enquanto que a projeção do fluxo de caixa consiste na previsão de entradas e saídas de caixa em um determinado período e envolve, portanto, o ciclo de caixa.

Porém, o nível de conhecimento dos gestores sobre o conceito de necessidade de investimento em capital de giro é um dos piores do conjunto pesquisado, visto que $56,9 \%$ dos respondentes manifestaram que têm parcos ou nenhum conhecimento sobre o assunto. Esse resultado assemelha-se ao encontrado por Domingues et al. (2017), que identificaram que 39\% dos microempreendedores não conheciam a necessidade de capital de giro ao iniciar as suas atividades empresariais.

No caso dos conceitos contábeis, os resultados da pesquisa podem ser sintetizados nos aspectos comentados na sequência.

Acerca dos conceitos de ativo circulante (AC) e passivo circulante (PC) foi constatado que estes são compreendidos por aproximadamente $60 \%$ dos gestores inquiridos, enquanto que a expressão "patrimônio líquido" (PL) é entendida por 69,9\% dos respondentes. Contudo, ao considerar somente as empresas não-fabris, os citados níveis de conhecimento caem para aproximadamente 58\% (AC e PC) e 68\% (PL). Além disso, 32\% dos respondentes alegaram que não conhecem suficientemente ou desconhecem totalmente a demonstração do resultado do período e o conceito de liquidez corrente foi o que apresentou o menor índice de conhecimento pelos gestores participantes do estudo.

A realidade citada implica considerar que praticamente $40 \%$ dos gestores participantes do estudo têm dificuldades para compreender quatro dos conceitos mais elementares da seara contábil e o demonstrativo básico sobre o desempenho econômico da empresa. Essa situação é preocupante e se assemelha às conclusões de Santos, Dorow e Beuren (2016) quando mencionaram que a falta de conhecimento dos gestores tem contribuído para que as decisões sejam tomadas de forma intuitiva, sem levar em consideração os demonstrativos contábeis e as informações gerenciais oriundas destes. Em virtude disso se pode dessumir que, devido ao baixo conhecimento sobre os conceitos contábeis, um conjunto relevante de informações que

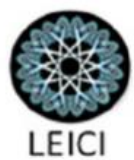


poderiam ser utilizadas pelos administradores dessas empresas não está sendo devidamente aplicado.

Então, com fulcro nos achados acima evidenciados, consideram-se convergentes os resultados do presente estudo com pesquisas anteriores (SANTOS; FERREIRA; FARIA, 2009; MONTEIRO; BARBOSA, 2011; ALBUQUERQUE et al., 2013; SANTOS; DOROW; BEUREN, 2016; KLEIN; ALMEIDA, 2017) no sentido da baixa utilização de artefatos da contabilidade. Nesse sentido, o insuficiente conhecimento dos gestores pode ser um dos motivos pelos quais um expressivo percentual de pequenas empresas não adota, de forma plena, práticas de gerenciamento financeiro capazes de contribuir para suportar as pressões mercadológicas, o que pode levar à mortalidade precoce desses empreendimentos.

\section{Conclusões}

O estudo objetivou identificar o nível de conhecimento sobre conceitos financeiros dos gestores de micros e pequenas empresas da microrregião da Amurel. Nesse sentido, considerase que tal objetivo foi atingido porque as respostas obtidas no questionário aplicado permitiram conhecer e analisar o grau de compreensão dos gestores de MPEs sobre os temas abrangidos.

Entre os resultados apurados é pertinente salientar que no mínimo 55\% dos gestores possuem conhecimento sobre os conceitos pesquisados, mas tal nível não ultrapassa os $75 \%$. Além disso, ao avaliar por segmento empresarial, constatou-se que os gestores das micros e pequenas indústrias possuem um conhecimento mais acentuado sobre os conceitos indagados de gestão financeira e contabilidade financeira na comparação com os gestores das MPEs comerciais ou de prestação de serviços.

Por outro prisma, os três conceitos menos conhecidos pelos gestores são, em ordem decrescente: liquidez corrente, ciclo operacional e necessidade de investimento em capital de giro. Entre os dois grupos de conceitos inquiridos (gestão financeira e contabilidade financeira), aquele com maior conhecimento dos gestores refere-se aos conceitos de contabilidade (com exceção da liquidez corrente), especialmente pelas empresas do setor industrial. Os resultados da pesquisa também demonstraram que o maior déficit de conhecimento dos gestores refere-se ao conceito de liquidez corrente.

Quanto à contribuição do estudo, esta concentra-se principalmente em oportunizar uma reflexão sobre o conhecimento e a utilização das informações contábeis no meio empresarial. Desse modo, o estudo pode contribuir com a Teoria da Contingência visto que a falta de conhecimento dos gestores sobre os conceitos abordados pode ser considerada um fator contingencial que tende a influenciar a utilização (ou não) dos mesmos no cotidiano das organizações. A pesquisa também corrobora estudos anteriores sobre o tema e demonstra que há um baixo índice de conhecimento dos gestores de MPEs sediadas no sul de Santa Catarina sobre os conceitos financeiros investigados.

No que concerne às limitações inerentes à pesquisa, cabe salientar que os resultados mencionados consideram as respostas obtidas como verídicas, mesmo que não se tenha prova documental para corroborar. Ou seja, assumiu-se que a escolha das respostas pelos participantes expressa a realidade das empresas que representam. Dessa forma, a subjetividade do questionamento pode ser considerada uma limitação da pesquisa. Adicionalmente, a pesquisa restringiu-se às 299 MPEs da microrregião da Amurel e seus achados devem ser considerados como limitados a este estrato amostral.
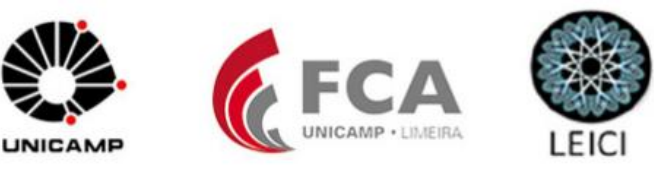
Como recomendação para pesquisas futuras sugere-se o cruzamento de informações para identificar se os gestores das MPEs que afirmaram conhecer os conceitos pesquisados utilizam-se deste conhecimento para aprimorar a gestão empresarial e se a utilização influencia o desempenho das MPEs.

\section{Referências}

ALBUQUERQUE, A. F. Gestão estratégica das informações internas na pequena empresa: estudo comparativo de casos em empresas do setor de serviços hoteleiro da região de Brotas. 2004. 209f. Dissertação (Mestrado em Engenharia da Produção) - Curso de Pós-Graduação em Engenharia de Produção, Escola de Engenharia de São Carlos, Universidade de São Paulo, São Paulo, 2004.

ALBUQUERQUE, E. M. N. et al. O uso de indicadores e relatórios contábeis para tomada de decisão nas micro e pequenas empresas do estado do Amazonas. Revista de Administração da UNIFATEA, v. 6, n. 6, p. 6-21, 2013.

ALMEIDA, D. M.; PEREIRA, I. M.; LIMA, I. J. Instrumentos de controle de gestão utilizados por micro e pequenas empresas sul catarinenses. Revista da Micro e Pequena Empresa, v. 10, n. 3, p. 49-92, 2016.

ALMEIDA, J. E. F. de; MARTINS, E. A. Demonstrações contábeis. In: ALMEIDA, J. E. F. de et al. Contabilidade das pequenas e médias empresas. Rio de Janeiro: Elsevier, 2014.

ASSAF NETO, A.; LIMA, F. G. Curso de administração financeira. São Paulo: Atlas, 2009. BORGES, L. F. M.; LEAL, E. A. Utilidade da informação contábil gerencial na gestão das micro e pequenas empresas: um estudo com empresas do programa empreender de Uberlândia - MG. Revista ReGePe, v. 4, n. 3, p. 116-146, 2015.

BRAGA, R.; NOSSA, V.; MARQUES, J. A. V. C. Uma proposta para a análise integrada da liquidez e rentabilidade das empresas. Revista Contabilidade \& Finanças, v. 15, n. especial, p. 51-64, 2004.

CAMPOS, B. R.; GÁUDIO, A. E. G. M. A utilização de ferramentas de controle gerencial em micro e pequenas empresas da Região Metropolitana do Rio de Janeiro. Revista da Micro e Pequena Empresa, v. 8, n. 3, p. 66-78, 2015.

CARVALHO, J. R. M.; LIMA, M. D. D. Práticas gerenciais em MPE's do comércio de confecções da cidade de Sousa - PB. Revista de Educação e Pesquisa em Contabilidade, v. 5, n. 3, p. 48-68, 2011.

COMITÊ DE PRONUNCIAMENTOS CONTÁBEIS - CPC 00 R1 (Estrutura Conceitual para Elaboração e Apresentação das Demonstrações Contábeis). Disponível em: http://www.cpc.org.br/CPC/Documentos-Emitidos/Pronunciamentos/Pronunciamento?Id=80. Acesso em: 29 de Novembro de 2017.

D’AMATO, C. L.; GALVÃO, M.; VILLAÇA, N. A. G.; JORGE, R. K.; TAVARES, Z. Curso básico de finanças: entendendo finanças de maneira prática e objetiva. São Paulo: Atlas, 2012. DOMINGUES, O. G. D.; TINOCO, J. E. P.; YOSHITAKE, M.; PAULO, W. L. de; CLARO, J. A. C. dos. Gestão de capital de giro e formação do preço de venda praticado pelas micro e pequenas empresas. Revista Ambiente Contábil, v. 9, n. 1, p. 77, 2017.

FERREIRA, C. C.; MACEDO, M. A. S.; SANT'ANNA, P. R.; LONGO, O. C.; BARONE, F. M. Gestão de capital de giro: contribuição para as micro e pequenas empresas no Brasil. Revista de Administração Pública, v. 45, n. 3, p. 863-884, 2011.

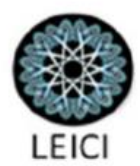


FREITAS, H.; OLIVEIRA, M.; SACCOL, A. Z.; MOSCAROLA, J. O método de pesquisa Survey. Revista de Administração. São Paulo. v35, p. 105-112, julho/setembro de 2000. GIL, A. C. Como elaborar projetos de pesquisa. São Paulo: Atlas, 2009.

KLEIN, L.; ALMEIDA, L. B. A influência dos fatores contingenciais na adoção de práticas de contabilidade gerencial nas indústrias paranaenses. Revista Universo Contábil, v. 13, n. 3, p. 90-119, jul./set., 2017.

KOS, S. R.; ESPEJO, M. M. dos S. B.; RAIFUR, L.; ANJOS, R. P. Compreensão e utilização da informação contábil pelos micro e pequenos empreendedores em seu processo de gestão. Enfoque: Reflexão Contábil, v. 33, n. 3, 2014.

LEMES JÚNIOR, A. B.; RIGO, C. M.; CHEROBIM, A. P. M. S. Administração financeira: princípios, fundamentos e práticas trabalhistas. Rio de Janeiro: Elsevier, 2005.

LIMA, A. N.; IMONIANA, J. O. Um estudo sobre a importância do uso das ferramentas de controle gerencial nas micros, pequenas e médias empresas industriais no município de São Caetano do Sul. Revista da Micro e Pequena Empresa, v. 2, n. 1, p. 28-48, 2008.

MAQBOOL, M. Q.; FAROOQ, U. Liquidity risk, performance and working capital relationship of cash conversion cycle: an empirical study of the firms in

Pakistan. International Journal of Information Research and Financial Review, v. 3, p. 1946-1951, 2016.

MARION, J. C. Contabilidade empresarial. 17a . ed. São Paulo: Atlas, 2015.

MARQUES, L.; SELL, F. F.; LAVARDA, C. E. F.; ZONATTO, V. C. da S. Artefatos da contabilidade gerencial: um estudo em cursos de graduação de ciências contábeis na região sul do Brasil. ConTexto, v. 16, n. 34, p. 1279-1299, 2016.

MARTINS, E. Contabilidade de custos. $9^{\mathrm{a}}$ ed. São Paulo: Atlas, 2003.

MARTINS, L. O. S.; SANTOS, P. H. O. Impactos da convergência contábil em índices econômicos e financeiros nas empresas baianas nos períodos de 2003 a 2007 e 2010 a 2014. Revista de Administração, Contabilidade e Economia da Fundace, v. 8, n. 1, 2016. MONTEIRO, J. M.; BARBOSA, J. D. Controladoria empresarial: gestão econômica para as micro e pequenas empresas. Revista da Micro e Pequena Empresa, v. 5, n. 2, p. 38-59, 2011. MOURA, L. C. A.; RÊGO, T. F. Concepção de ativos: um estudo sobre a compreensão dos discentes do curso de graduação em ciências contábeis da UFERSA. Revista Reunir, v. 4, n. 2, p. 20-42, 2014.

OLIVEIRA, J.; ESCRIVÃO FILHO, E.; NAGANO, M. S.; FERRAUDO, A. S. Estilos gerenciais dos dirigentes de pequenas empresas: estudo baseado no ciclo de vida organizacional e nos conceitos de funções e papéis do administrador. Revista Brasileira de Gestão de Negócios, v. 17, n. 57, p. 1279-1299, 2015.

PANOSSO, A.; CAMANHO, R. R.; ESPEJO, M. M. dos S. B.; ABBAS, K. Influência das ferramentas de controle gerencial no desempenho: estudo empírico em empresas industriais paranaenses. Enfoque: Reflexão Contábil, v. 36, n. 2, p. 1, 2017.

RAUPP, F. M; MARTINS, S. J.; BEUREN, I. M. Utilização de controles de gestão nas maiores indústrias catarinenses. Revista Contabilidade \& Finanças, v. 17, n. 40, p. 120-132, 2006.

RESNIK, P. A Bíblia da pequena empresa: como iniciar com segurança sua pequena empresa e ser bem-sucedido. Tradução de Maria Claudia Oliveira Santos; Revisão Técnica Heitor José Pereira. São Paulo. Mc Graw-Hill: Makron Books, 1990.

RICHARDSON, R. J. el al. Pesquisa social: métodos e técnicas. $3^{\text {a }}$ ed. São Paulo: Atlas, 1999.

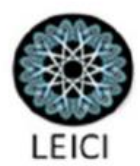


SANTOS, F. de A.; VEIGA, W. E. Contabilidade: com ênfase em micro, pequenas e médias empresas. 3. ed. São Paulo: Atlas, 2014.

SANTOS, L. M. D.; FERREIRA, M. A. M.; FARIA, E. R. Gestão financeira de curto prazo: características, instrumentos e práticas adotadas por micro e pequenas empresas. Revista de Administração da Unimep, v. 7, n. 3, p. 70-92, 2009.

SANTOS, V.; DOROW, D. R.; BEUREN, I. M. Práticas gerenciais de micro e pequenas empresas. Revista Ambiente Contábil, v. 8, n. 1, p. 153-186, 2016.

SCALZER, R. S.; AZIZ, X. B.; REINA, D. Adoção do icpc01 e a lei 12.783/13: reflexos no reconhecimento dos ativos financeiros de concessão. Revista Universo Contábil, v. 12, n. 3, p. 49, 2016.

SERVIÇO BRASILEIRO DE APOIO ÀS MICRO E PEQUENAS EMPRESAS. SEBRAE. Fatores condicionantes e taxas de sobrevivência e mortalidade das micro e pequenas empresas no Brasil 2003-2005. Brasília, DF, 2007. Recuperado de <http://www.biblioteca.sebrae.com.br/bds/bds.nsf/8F5BDE79736CB99483257447006CBAD 3/\$ File/NT00037936.pdf>. Acesso em: 04 dezembro 2017.

SERVIÇO BRASILEIRO DE APOIO ÀS MICRO E PEQUENAS EMPRESAS. SEBRAE. Participação das Micro e Pequenas Empresas na Economia Brasileira. Brasília, DF, 2014. Recuperado <https://m.sebrae.com.br/Sebrae/Portal\%20Sebrae/Estudos\%20e\%20Pesquisas/Participacao\% 20das\%20micro\%20e\%20pequenas\%20empresas.pdf $>$. Acesso em 30 novembro 2017.

SOUSA, Thiago Ferreira de. Uma análise sobre a relação entre o retorno de empresas brasileiras e os componentes do ciclo de conversão de caixa. Dissertação (Mestrado Profissional em Finanças e Economia) - FGV - Fundação Getúlio Vargas, São Paulo, 2016.

SOUZA, A. F. Estratégia, crescimento e a administração do capital de giro. Caderno de Pesquisa em Administração, Programa de Pós-Graduação, FEA, USP, v.2, p.12, 1997.

STROEHER, A. M.; FREITAS, H. Identificação das necessidades de informações contábeis de pequenas empresas para a tomada de decisão organizacional. In: III Congresso Internacional de Gestão da Tecnologia e Sistemas de Informação - CONTECSI, 3, 2006, São Paulo. Anais... CONTECSI, 2006.

WERNKE, R.; JUNGES, I. Níveis de utilização e importância atribuídos aos principais demonstrativos contábeis por 207 empresas do sul de Santa Catarina. In: VII Congresso Nacional de Administração e Contabilidade - AdCont, 8, 2016, Rio de Janeiro. Anais... Rio de Janeiro, FGV, 2016.

WERNKE, R.; JUNGES, I.; LEMBECK, M.; RUFATTO, I. Utilização e importância atribuída à projeção do fluxo de caixa operacional por 207 empresas da microrregião da AMUREL. In: VI Congresso Brasileiro de Engenharia de Produção - Conbrepro, 7, 2016, Ponta Grossa (PR). Anais... Ponta Grossa, Aprepro, 2016. 